\title{
Integrated Product Development at Nestlé
}

\author{
Namy Espinoza-Orias, Karen Cooper and Sofiane Lariani
}

\begin{abstract}
Nestlé's purpose is to enhance the quality of life and contribute to a healthier future. In practice, it is translated into product development through a life cycle, multi-criteria, and integrated approach engaging internal and external stakeholders. An overview of the company's values is presented as well as its creating shared value business principles, followed by an explanation of the Sustainability by Design program and how it is embedded into product innovation and renovation. The integrated development of a breakfast solution for children who skip breakfast exemplifies this approach. Being proactive and understanding that what matters to consumers entails all aspects of the product-going beyond quality and including sustainability - enriches the product development process, informs decision-making timely, provides consumers with a product they prefer, delivers competitive advantage, and supports the fulfilment of Nestlé's public commitments.
\end{abstract}

\section{Introduction}

In 2016, Nestlé celebrated its 150th anniversary and is currently the largest food and beverage company worldwide. From the beginning, when Henri Nestlé invented the Farine Lactée to save the life of an infant, Nestlé's purpose has been to enhance the quality of life and contribute to a healthier future. What drives our value creation, both for business and society, is a nutrition, health and wellness strategy. With more than 2000 brands, whose products are sold across seven product categories in 191 countries, understanding and anticipating consumer needs in an ever evolving and competitive environment is imperative for Nestlé's long-term business success. This is precisely the starting point of our integrated product development. It follows a life cycle, multi-criteria process, with the engagement of

\footnotetext{
N. Espinoza-Orias $(\bowtie) \cdot$ K. Cooper $\cdot$ S. Lariani

Nestlé Research Center, Rue Du Jorat 57, 1000 Lausanne, Switzerland

e-mail: NamyDaniela.EspinozaOrias@rdls.nestle.com

(C) The Author(s) 2018

E. Benetto et al. (eds.), Designing Sustainable Technologies,

Products and Policies, https://doi.org/10.1007/978-3-319-66981-6_50
} 
internal and external stakeholders and the firm inclusion of Nestlé's values, business principles and public commitments against which our company and products are held accountable.

The purpose of this paper is to explain how key elements bring in practice product innovation and renovation with a competitive advantage. Our values framework, business model, Sustainability by Design program and integrated product development approach are reviewed. A breakfast solution for schoolchildren who skip breakfast is presented as an example of consumer-centric product development.

\section{Creating Shared Value, the Nestlé Way}

Guided by values rooted in respect, Nestlé works alongside partners and stakeholders to create shared value (CSV) across all the activities of the company, which contribute to society while ensuring the long-term success of our business.

Three interconnected focus areas are identified wherein our purpose is realized:

(1) Individuals and families: to whom Nestlé offers products and services that enable them to lead healthier and happier lives.

(2) Our communities: helping those we live and work with in developing into thriving and resilient communities, enhancing rural livelihoods, and respecting and promoting human rights.

(3) Our planet: stewarding resources for the future, caring for water, acting on climate change and shaping sustainable consumption.

Our CSV priorities and efforts are supported by 42 specific, public commitments with clear short-term timelines (2020) as well as three overarching medium term (2030) ambitions for our focus areas. In particular, Nestlé aims to help 50 million children lead healthier and happier lives, help improve the livelihoods of 30 million in communities directly connected to our business activities and strive for zero environmental impact in our business operations [1].

The recently updated and reframed commitments as well as newly introduced ones [1] go further and deeper than the first set of them launched back in 2012. The commitments were defined taking into account stakeholder recommendations and issues material to our consumers, stakeholders and the company. The materiality assessment is carried out every two years in collaboration with SustainAbility - an independent consultancy specialized in corporate sustainability - using a formal process entailing extensive consultations of stakeholders, investors and key opinion leaders. Issues of concern in the environmental, social and governance areas are identified and assessed in order to determine their business impact in terms of risks and opportunities along with the level of interest stated by stakeholders. The commitments were also aligned in scope and timeline with the Sustainable Development Goals (SDGs) [2]. 
In particular, those SDGs where Nestlé has specific responsibilities as a member of the private sector and can have the most positive and meaningful impact are emphasized. This is achieved by mapping our material issues to the SDGs; as a result, it is possible to find where our activities contribute, directly or indirectly, to the realization of the SDGs.

\section{Sustainability by Design}

In order to embed sustainability into our products, the Sustainability by Design program led by the Nestle Research organization assesses the sustainability aspects at the earliest phase of the product development cycle. The aim is to optimize the impacts across the entire value chain through an iterative approach that spans the product development process. The various elements taken into account are schematised in Fig. 1.

From the early stages of a product development, projects are systematically evaluated with the following steps:

(1) Identification - as early as possible - of the opportunities or hotspots, either environmental or social. A tool has been developed that guides projects through the process of discussing its potential impact on individuals and families, our communities and the planet. Project managers collaborate with sustainability

\begin{tabular}{|c|c|c|}
\hline \multicolumn{2}{|c|}{ WHEN TO ASSESS? } & WHERE IN THE VALUE CHAIN? \\
\hline \multicolumn{2}{|c|}{$\begin{array}{l}\text { At the various stages of the } \\
\text { Produa Development Process }\end{array}$} & $\begin{array}{l}\text { At the various } \\
\text { life cycle stages of the product }\end{array}$ \\
\hline \multicolumn{2}{|l|}{ 1. Ideation } & 1. Agricultural production of ingredients \\
\hline \multicolumn{2}{|c|}{ 2. Conceptualization } & 2. Manufacture of packaging materials \\
\hline \multirow{2}{*}{\multicolumn{2}{|c|}{ 3. Development }} & 3. Manufacture of food products \\
\hline & & 4. Distribution \\
\hline \multicolumn{2}{|c|}{ 5. Launch } & 5. Retail \\
\hline \multirow{2}{*}{\multicolumn{2}{|c|}{ 6. Post-Launch }} & 6. Consumption \\
\hline & & 7. End of life \\
\hline \multicolumn{2}{|c|}{ WHO IS IMPACTED? } & WHAT IS ADDRESSED? \\
\hline \multicolumn{2}{|c|}{ Intemal and external stakeholders } & Contribution through our products to: \\
\hline 1. Farmers & 5. Pets & 1. Nestlé Public Commitments \\
\hline 2. Suppliers & 6. Families & 2. Materiality issues \\
\hline 3. Employees & 7. Communities & 3. Ambitions for our focus areas \\
\hline 4. Consumers & 8. The planet & 4. Sustainable Development Goals \\
\hline
\end{tabular}

Fig. 1 Elements considered in the sustainability assessment of products at Nestlé 
champions to identify which societal commitments their project may affect, positively or negatively. This is revisited at key moments in the project, i.e. when passing a stage gate or a major change occurs.

(2) Comparison to the Nestlé materiality matrix (Fig. 2), which summarizes the issues of concern to the company and its stakeholders. As the 42 commitments are not exhaustive to all potential issues, this enables project managers to understand if their project may assist in other areas of concern.

(3) An action plan is developed to either mitigate or leverage the potential impacts and is then recorded as part of the project process. The actions can consist of carrying out further in-depth assessments as the project progresses and more information becomes available.

(4) The tool covers every step in the value chain from ingredients, processing in our factories, packaging, consumer use right through to end of life. It allows a deep dive into specific aspects; for example, into ingredients and responsible sourcing, linking into the Procurement side of the company.

(5) At this point, a project is also assigned a specific rating for potential environmental sustainability impact, which is a key KPI tracked at a strategic level across the project portfolio. This tracking allows the calculation of time spent on projects of different ratings, an important indicator as to whether the portfolio will deliver against our environmental commitments. This rating can be reviewed or ratified at various points in the project process.

(6) The assessment itself ends at this point, having taken approximately an hour but delivering key information on how the project will deliver against sustainability and an action plan for improvement.

Following up on the agreed actions usually involves the use of EcodEX, a simplified environmental life cycle assessment tool developed with an outside IT company, Selerant [3]. This tool allows the comparison of multiple scenarios, for instance a current product in the market versus an innovation. Early use allows detailed quantitative information on potential environmental issues and benefits to be available for decision making at a point where there is more design freedom and less cost to make changes.

Future potential work to develop this tool may include a stronger social focus and Nestlé is evaluating the latest methodologies in this area.

\section{Integrated Product Development}

\subsection{PrIME}

Consumer centric product development, renovation or innovation must also take into account the different elements influencing the decision to buy food and beverage products. These are taste, price, healthiness, convenience and sustainability [4]. 


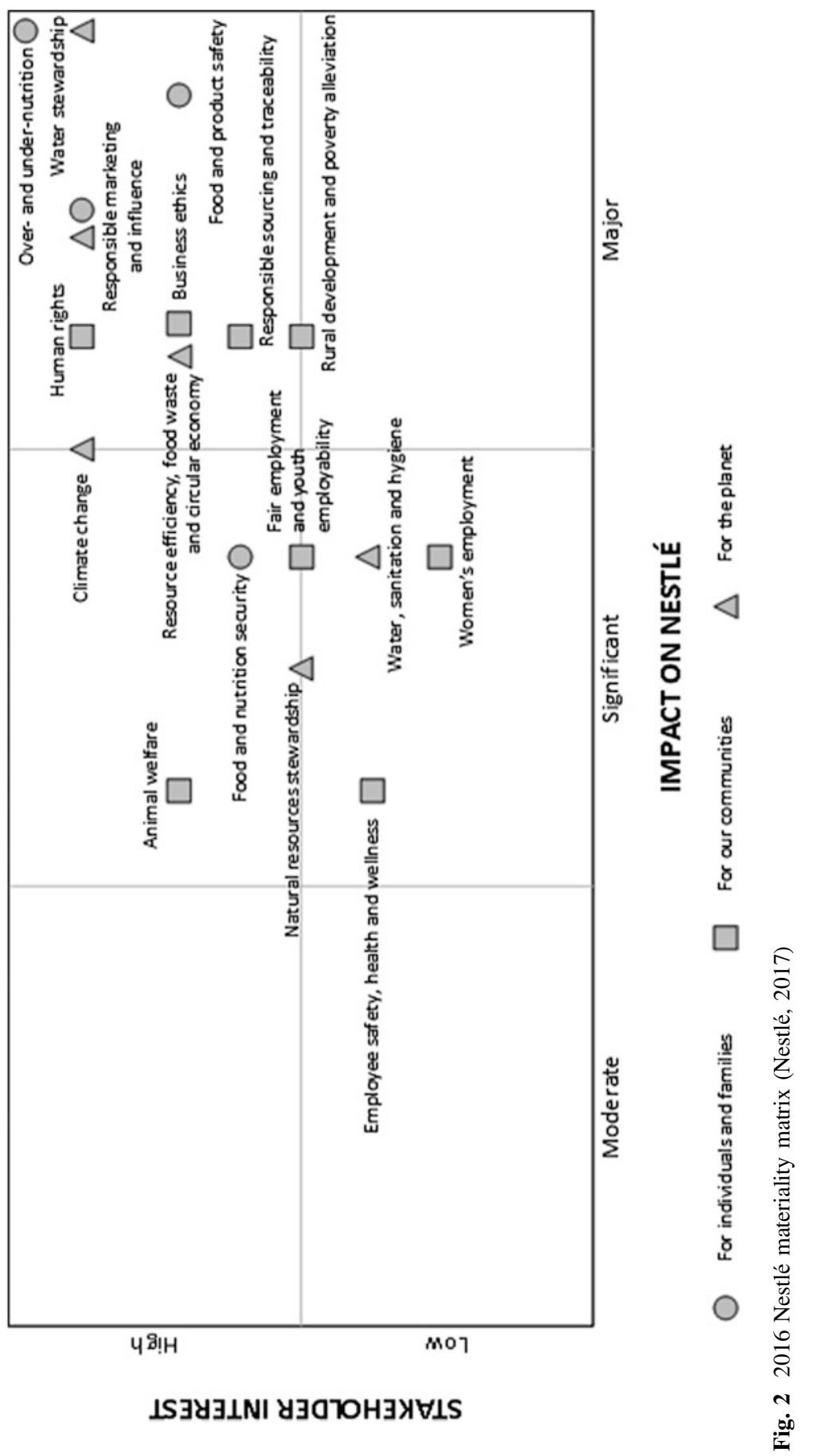


The incremental approaches optimizing one element at the time in a complex environment where Nestlé has to come up with heathy, sustainable products that the consumer wants and can afford, have quickly shown their limitations.

Therefore, Nestlé Research put in place a holistic approach, called PrIME, optimizing at the same time consumer healthiness, preference, sustainability and affordability. Integrating these four elements into product development through deep understanding of consumer needs and preferences has helped identifying optimal recipes by maximizing these different elements simultaneously.

Nestlé is applying the PrIME approach to product design and packaging to optimize the whole product experience by:

(1) Mastering healthiness and sensorial product features. For example, delivering product sweetness with less sugar through optimal product design.

(2) Improving the packaging functionality to ensure:

1. Inclusions of all individuals (for instance the elderly), and

2. Frustration free packaging experience.

Nestlé Research has developed this consumer centric product development approach in all key global brands for the past years and we are now deploying it in the main markets to support our local brands.

This consumer-centric approach is built around a process that uses a collection of standardized methodologies and tools to connect people understanding and product knowledge. The management of our knowledge and data is the foundation of this process and the way to accelerate it, iteration after iteration. Therefore, several activities are in place to optimize the management and sharing of consumer and product knowledge and data. PrIME is using data from different sources and big data techniques to ensure we constantly satisfy the evolution of needs of individuals and families.

PrIME consists of the following steps:

(1) Identification of consumer value drivers: what is important for the individuals and families? How do they like consuming their products? What are their needs? What are their dissatisfactions? This first step is important to dive into the heart of the consumer preferences but not sufficient to decode individuals and family's needs.

(2) Understanding people needs and behaviours is at the heart of this approach. We use state of the art consumer research to translate multi-dimensional needs into objective product features and attributes.

(3) Consumer centric product and technological mastership is ultimately the way to:

a. Fast track product development. b. Identify our product knowledge gaps and develop innovative, differentiating and sustainable technologies to better satisfy the consumer on the elements cited above: healthiness, preference, sustainability and affordability. c. Control our manufacturing settings and provide day after day high and sustainable product quality to individuals and families. 
The PrIME approach has shown its success developing efficiently and effectively the products the consumer wants first time right and contributes to push us to constantly innovate in technologies relevant for consumers, communities and the planet.

\subsection{Nutritional Considerations for Product Development at Nestlé}

Nestlé Research developed in 2004 the Nestlé Nutritional Profiling System (NNPS) that guides the nutritional dimension of formulation and reformulation of Nestlé products nutritional product development [5]. The NNPS translates nutritional recommendations from the World Health Organization and other international and national organizations - taking also technical feasibility into account - into tangible product targets, e.g. the amounts of nutrients to limit and nutrients to encourage in a product. If all targets defined by the NNPS are met, then the product achieves the Nutritional Foundation (NF). The nutritional assessment is facilitated through a tool, globally rolled out in Nestlé and used by more than 1000 product developers and nutritionists. This assessment is a fundamental step within the development process and guides further improvements in the products.

\section{Case Study: Nestlé Nido GoldenStart $\subset$}

Although breakfast is considered the most important meal of the day, it is common that children skip breakfast frequently, thus missing the opportunity to consume a meal rich in nutrients recommended for a wholesome diet. Existing studies and reviews on breakfast consumption habits in different regions and countries [6-8] report that between 10 and $30 \%$ of schoolchildren skip breakfast.

The reasons leading to skipping breakfast are varied, and include socio-demographic factors, limited nutritional knowledge, lack of time and planning for breakfast (preparation and/or consumption), absence of hunger in the morning, limited or no availability of breakfast foods that are affordable and convenient, as well as concerns about body weight [9-11].

A review was made to summarize recommendations for a complete, healthful breakfast in order to offer guidance on its ideal composition and energy intake [12, 13]. A breakfast should provide between 20 and $25 \%$ of the overall daily energy intake, a range that already takes into account the number of eating occasions in a day (breakfast, lunch, dinner and snacks). A complete breakfast meal should consist of solid and liquid foods, with the purpose of maximizing nutrient intake and reducing or closing nutrient gaps. Foods containing protein, whole grains, fruits and vegetables are specifically recommended. 
Following the holistic approaches described earlier (Sustainability by Design, PrIME and nutritional assessment through the NNPS), Nestlé developed a breakfast solution targeting the segment of schoolchildren aged 4-8 who are breakfast skippers. This product, marketed under the brand Nido GoldenStart $\mathrm{C}$, provides the right combination of essential nutrients required for breakfast and $12 \%$ of the daily energy intake for this age group. Its ingredients are milk, cereals and fruits, delivered in a convenient ready to drink format (beverage carton, $200 \mathrm{ml}$ ). A first generation of the product (powder beverage) was launched in Central America in 2015; a second generation ready to drink version was launched in Ecuador in September 2017.

The various steps followed in the integrated product development process can be recapped as follows:

(1) Consolidation of consumer data: The drivers of preference, expressed in terms of sensory attributes (taste, texture, aroma, colour, etc.) were identified by mining internal consumer insight data.

(2) Definition of the right nutritional targets through the NNPS and a project to define specific nutritional targets for complete breakfasts and "breakfast-on-the-go".

(3) Product and process mastership: Product experts at Research and Development units as well as factories represented the key unit operations required to screen the potential ingredients, design the recipe, define the process parameters and finally manufacture the product.

(4) A large number of possible recipes was reduced to an optimal number. These recipes were produced for consumer trials considering factors such as consumer and sensory data, recipe cost and technical constraints.

(5) Preference mapping: The recipes most liked by parents and children were selected and the reasons for liking or disliking them were explored. In parallel, a monadic sensory profiling was performed with an expert panel to understand the consumers' feedback. A satiation test was also conducted to assess the effect of the product texture on satiation and thus validate the portion size.

(6) Validation test: The superiority of the final recipe was validated using a number of internal methods, among which the Nutritional Foundation (NF) and 60/40+ taste preference criteria can be highlighted. 60/40 is a Nestlé method whereby consumers are asked to state their preference in a blind test between an own product and a competitor or benchmark. A Nestlé product passes the test when more than $60 \%$ of the consumers would prefer it to the competitor product or benchmark. The "+" equals achieving the Nutritional Foundation, meaning all nutritional targets defined by the NNPS are met.

(7) Environmental sustainability evaluation: The eco-design of the product was carried out using the EcodEX tool. On a basis of 100 kilocalories delivered, Nido GoldenStart $(\mathrm{C}$ showed improved environmental performance on all five environmental indicators assessed (climate change, freshwater consumption scarcity, abiotic depletion, ecosystems quality and land use impact on biodiversity) when compared to a reference product. 
Moreover, the integrated development of Nido GoldenStart $\subset$ satisfies a clear consumer need while contributing to the achievement of Nestlé commitments on:

(1) Inspiring people to lead healthier lives: Empower parents to foster healthy behaviours in children (not skipping breakfast).

(2) Offering tastier and healthier choices: Launching more nutritious foods and beverages especially for children. Increase the fibre and grains content in our foods and beverages.

(3) Safeguarding the environment: Assess and optimize the environmental impact of our products.

\section{Conclusions}

This holistic and comprehensive approach, as applied by Nestlé, delivers competitive advantage, leads to the fulfilment of public commitments at company level and drives our contribution as member of the food industry to the attainment of the Sustainable Development Goals. Informed decision-making takes place at the various steps of project execution, risks and opportunities are identified, with early warning brought up in a timely manner.

However, given the breadth of technical areas concerned and what is at stake, the interpretation of data and insights resulting from this way of working can be complex and raise some challenges. The deployment of support tools can only be justified as long as they are used properly and extensively. Deciding which business function will take up the identified actions for improvement, either Research and Development, Operations, Markets or a combination requires alignment of objectives and priorities as well as clear allocation of resources. For a company as large as Nestlé, it is fundamental to progress from starting the conversation and raising awareness on integrated product development, to consistently accomplishing it.

Being proactive and understanding that what matters to consumers entails all aspects of the product-going beyond quality and including sustainability - enriches the product development process and provides consumers with a product they prefer.

\section{References}

1. https://www.nestle.com/asset-library/documents/library/documents/corporate_social_responsibility/ nestle-csv-full-report-2017-en.pdf. (Accessed 04.04.2018).

2. http://www.un.org/ga/search/view_doc.asp?symbol=A/RES/70/1\&Lang=E. (Accessed 30.05. 2017).

3. http://www.selerant.com/eco-design/. (Accessed 30.05.2017).

4. http://www.foodinsight.org/sites/default/files/2016-Food-and-Health-Survey-Report_FINAL1. pdf. (Accessed 30.05.2017). 
5. Vlassopoulos A, Masset G, Rheiner Charles V, Hoover C, Chesneau-Guillemont C, Leroy F, Lehmann U, Spieldenner J, Tee E-S, Gibney M, Drewnowski A, A nutrient profiling system for the (re)formulation of a global food and beverage portfolio, European Journal of Nutrition, Vol. 56, 2016, pp. 1-18.

6. Rampersaud G, Pereira M, Girard B, Adams J, Metzl J, Breakfast habits, nutritional status, body weight, and academic performance in children and adolescents, Journal of the American Dietetic Association, Vol. 105, No. 5, 2005, pp. 743-760.

7. Deshmukh-Taskar P, Nicklas T, O'Neil C, Keast D, Radcliffe J, Cho S, The relationship of breakfast skipping and type of breakfast consumption with nutrient intake and weight status in children and adolescents: The National Health and Nutrition Examination Survey 1999-2006, Journal of the American Dietetic Association, Vol. 110, No. 6, 2010, pp. 869-878.

8. Utter J, Scragg R, Mhurchu C.N, Schaaf D, At-home breakfast consumption among New Zealand children: Associations with body mass index and related nutrition behaviors, Journal of the American Dietetic Association, Vol. 107, No. 4, 2007, pp. 570-576.

9. Sweeney N, Horishita N, The breakfast-eating habits of inner city high school students, Journal of School Nursing, Vol. 21, No. 2, 2005, pp. 100-105.

10. Malinauskas B, Raedeke T, Aeby V, Smith J, Dallas M, Dieting practices, weight perceptions, and body composition: a comparison of normal weight, overweight, and obese college females, Nutrition Journal, Vol. 5, 2006, p. 11.

11. Reddan J, Wahlstrom K, Reicks M, Children's perceived benefits and barriers in relation to eating breakfast in schools with or without Universal School Breakfast, Journal of Nutrition Education and Behaviour, Vol. 34, No. 1, 2002, pp. 47-52.

12. O'Neil C, Byrd-Bredbenner C, Hayes D, Jana L, Klinger S, Stephenson-Martin S, The role of breakfast in health: Definition and criteria for a quality breakfast, Journal of the Academy of Nutrition and Dietetics, Vol. 114, No. 12, Suppl. 3, 2014, pp. S8-S26.

13. Vlassopoulos A, Nutrition criteria to be considered for breakfast drink innovation, Nestlé Research Center, 2017 (Internal note).

Open Access This chapter is licensed under the terms of the Creative Commons Attribution 4.0 International License (http://creativecommons.org/licenses/by/4.0/), which permits use, sharing, adaptation, distribution and reproduction in any medium or format, as long as you give appropriate credit to the original author(s) and the source, provide a link to the Creative Commons license and indicate if changes were made.

The images or other third party material in this chapter are included in the chapter's Creative Commons license, unless indicated otherwise in a credit line to the material. If material is not included in the chapter's Creative Commons license and your intended use is not permitted by statutory regulation or exceeds the permitted use, you will need to obtain permission directly from the copyright holder. 